Research Article

www.jestr.org

\title{
Introduction of Geophysical Technics in Marine Investigation
}

\author{
A. H. Jamali ${ }^{*}$ and B. M. Dehghani.
}

Geotechnical Engineering, Civil Department of Hormozgan University, Iran

Received 25 August 2013; Accepted 25 November 2013

\begin{abstract}
Exploration of the oceans has always engaged the attention of mankind however, the past few decades have seen an increasing intensity of exploration as scientists. Geotechnical investigations are an essential prerequisite for design of offshore structure to support safely the gravity and environmental loads to which they are subjected. Geophysical investigation in marine's been common in important marine projects. However geophysical investigation is not as common as geotechnical investigation but that science is growing recently. In this article we want to present and review of methods and instruments obviously. This article can be useful for geotechnical engineering.
\end{abstract}

Keywords: Exploration of the oceans, geotechnical investigation, Geophysical investigation.

\section{Introduction}

A high-resolution geophysical survey will creat an understanding of the general condition surrounding the site, and assist in identifying potentially hazardous geological features.it provides invaluable data on the stratigraphy and the degree of uniformity of the soil condition in the area.ploessel contend that geophysical data provide the following benefits:

i. Economic benefits, by limiting the required number of boring.

ii. Correlations with soil boring data;

iii. Detection of three-dimensional features over a large area;

iv. Understanding of geological setting that may not be easily detected by data from borings.

The range of modern geophysical instruments available to surveyors and engineers is extensive and their capabilities manifold. Only the briefest treatment of the more common systems is given here these instruments are categorised as:[1]

i. High-resolution reflection systems - using sound (acoustic energy) and measuring where the energy is 'reflected' from a geological horizon or seabed.

ii. Seismic refraction systems - using sound energy and measuring where the energy is 'refracted' along geological horizons.

iii. Electrical resistivity systems - using electrical energy and measuring the resistance of a bulk of nearseabed soil.

Figure 1 shows types of geophysical methods nutshell.

\footnotetext{
*E-mail address: jamali.phd@hormozgan.ac.ir

ISSN: 1791-2377 (C) 2013 Kavala Institute of Technology. All rights reserved.
}

This section also provides an overview of remotely operated platforms, seabed classification methods and underwater cameras. [2]

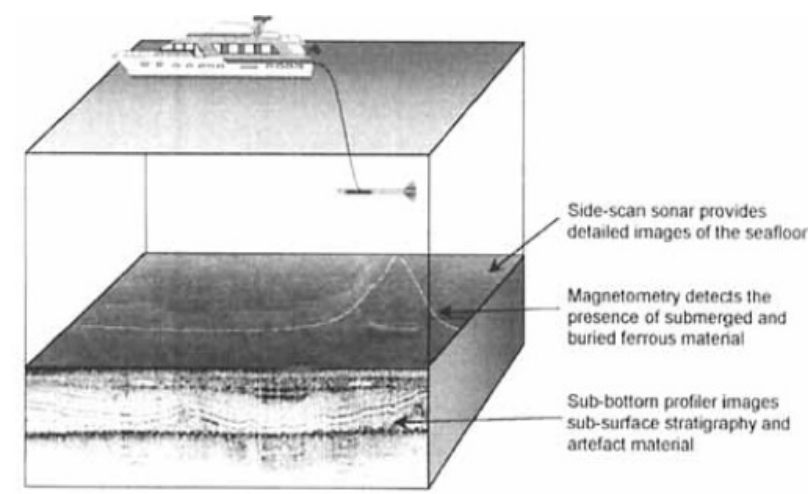

Fig.1. Towed devices for geophysical surveys

\section{High-Resolution Reflection Systems}

Geophysical survey systems use sound or, at close quarters, laser light, to make measurements of the seabed and the subseabed. The sensors tend to fall into three categories:[3]

i. Seabed measuring systems, e.g. echosounders, multibeam sounders.

ii. Imaging sensors, e.g. sidescan sonar, laser-scan, acoustic scanning systems.

iii. Sub-bottom profilers, e.g. pingers, boomers etc.

Information from high-resolution reflection systems requires the interpretation of reflections from the top of subsoil geological formations (reflectors). It is important to note that these systems define the boundaries between geological formations, but provide more qualitative than quantitative 
information on soil characteristics, hence the need for calibration information, e.g. from boreholes and sampling, for complementary geotechnical assessment in a process known as 'ground truthing'.

The most common combinations of system sensors for engineering applications are followed.

\subsection{Bathymetry systems}

\subsubsection{Echosounders}

The echosounder measures water depth from the two-way travel time of a high frequency pulse emitted by a transducer[4].The system must be calibrated to eliminate errors introduced by temperature and salinity and other factors that affect sound velocity. The choice of echosounder depends on factors including accuracy requirements, depth of water and achievable resolution. Typical frequencies range from $10 \mathrm{kHz}$ to $200 \mathrm{kHz}$. Until the introduction of swath instruments, echosounders were single beam devices, operating vertically below the survey vessel to gather a single line of soundings. Excluding the more sophisticated deep water systems, echosounders can be fitted to most vessels either by an over-the-side mount or through a special opening in the ship's hull.

\subsubsection{Swath Echosounders}

Multibeam, or interferometric swath echosounders, have become increasingly common and provide the geophysicist with a powerful seabed-modelling tool. Each transducer produces a fan of acoustic beams to provide sounding information either side of a vessel's track. The highperformance systems have wide-angle swaths that cover an area up to 10 times water depth. As water depth increases, range increases, but maximum range becomes limited due to acoustic energy depletion at the outer beams. The accuracy of swath systems is critically dependent on the corrections applied to remove vessel motion. The chief advantage of swath bathymetry systems is the high rate of productivity and excellent data sample density.

\subsubsection{LIDAR}

In shallow, clear waters (typically less than $30 \mathrm{~m}$ to $50 \mathrm{~m}$ deep and with relatively low concentrations of suspended solids), air-borne, laser scanning systems known as LiDAR are becoming increasingly common. Two laser frequencies are used; red light for reflecting from the sea surface, and green light to penetrate to the seabed. The difference between the two measurements is the water. For areas of significant extent, these systems are very efficient and, despite their apparent high-costs, can be very cost-effective in the coastal zone. Typically, the more modern LIDAR is as accurate than multibeam.

\subsection{Sidescan Sonar}

Sidescan sonars provide an acoustic, oblique, photo-like image of the seafloor. By ensonifying a swath of seabed and measuring the amplitude of the back-scattered return signals, an image is acquired of objects on the seabed and information on the morphology (the different materials and features comprising the seabed surface). High-frequency sonar (c. $500 \mathrm{kHz}$ ) provide high-resolution images, but with short $(<100 \mathrm{~m})$ ranges. Lower frequency systems (c. 60 $\mathrm{kHz}$ ) provide longer ranges, but with lower resolution. Developments to overcome this problem include using a second vessel (chase boat) to track the fish directly from above or deploying the sidescan on a remote platform. Figures 2 shows sidescan sonar and image is caused by that.

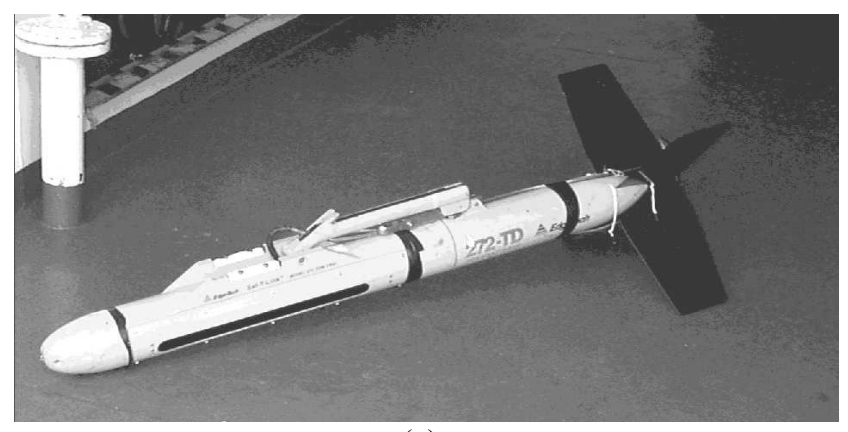

(a)

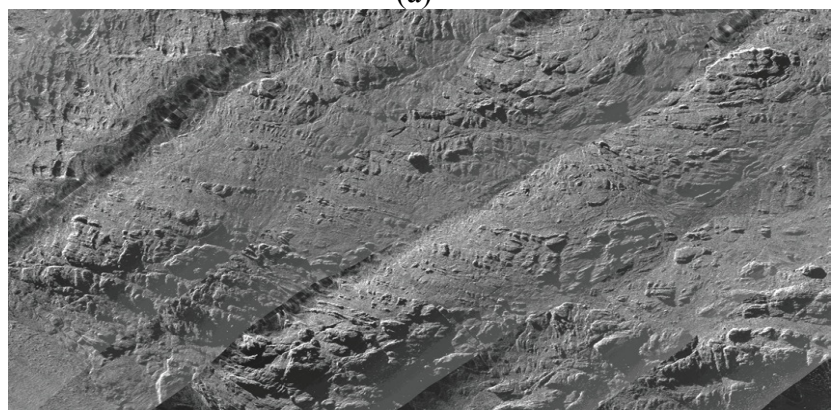

(b)

Fig. 2. (a) Edgetech sidescan sonar, (b) Sidescan sonar image of seabed.

\subsection{Sub-bottom profilers}

Sub-bottom profilers, sometimes referred to as single channel systems, are used throughout the industry for the shallowest sort of seabed profiling.[5]

\subsubsection{Pingers}

So-called because of their high frequency acoustic 'pings', pingers operate on a range of single frequencies between 3.5 $\mathrm{kHz}$ and $7 \mathrm{kHz}$, and can achieve seabed penetration from just a few metres to more than $50 \mathrm{~m}$. They are capable of resolving soil layers to approximately $0.3 \mathrm{~m}$. These highfrequency profilers are particularly useful for delineating shallow lithology features such as faults, gas accumulations and relict channels. in figure 3 we have a Pinger.

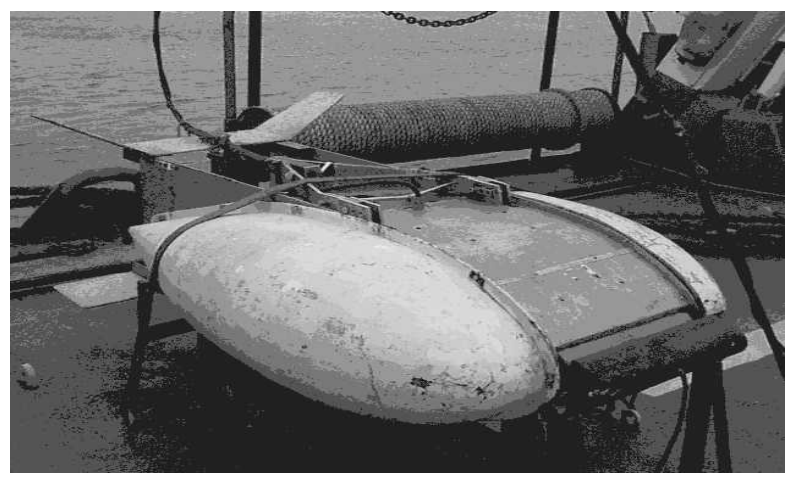

Fig. 3. Pinger sub-bottom profiler

\subsubsection{Boomers}

These instruments have a broader band acoustic source, between $500 \mathrm{~Hz}$ to $5 \mathrm{kHz}$, and can typically penetrate the seabed to between $30 \mathrm{~m}$ and $100 \mathrm{~m}$ with resolution of $0.3 \mathrm{~m}$ to $1.0 \mathrm{~m}$. Boomers make excellent generalpurpose geophysical profilers. 


\subsubsection{Sparkers}

These very powerful instruments can penetrate soils and rocks to $1000 \mathrm{~m}+$, but because of their unstable pulse waveform, are not in such common use as formerly.

\subsubsection{Chrip}

It Designed to replace the pingers and boomers, Chirp systems operate around a central frequency between $3 \mathrm{kHz}$ to $40 \mathrm{kHz}$ and can improve resolution in suitable nearseabed sediments. The single channel acoustic systems provide an excellent range of tools for remotely imaging near-surface soils and rocks. Care is needed not to overreach their capabilities. Figure 4 shows usTypical seafloor penetration ranges of geophysical systems.

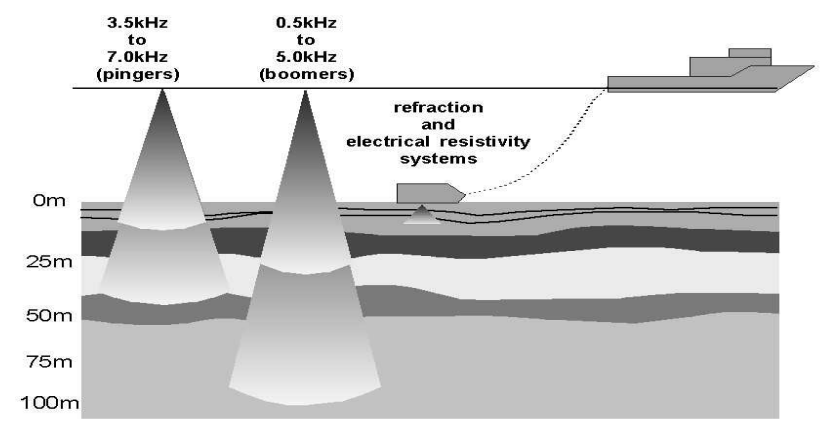

Fig. 4. Typical seafloor penetration ranges of geophysical systems

\section{Seismic Refraction Systems}

Seabed refraction seismic is a method of acquiring highresolution information of soil sedimentary structures.[6],[7] Refraction systems are typically employed where fine detail is required of the first $3 \mathrm{~m}$ of the seabed, and especially the topmost $1 \mathrm{~m}$. The most common application is as a burial assessment tool for submarine cable installation and for pipeline route investigations. A seismic source at the seabed is used to induce an acoustic pressure wave into the soil. In shallow water (typically $<250 \mathrm{~m}$ ), an airgun is used. As the pressure wave passes through the soil layers, some of its energy is refracted along sedimentary boundaries before returning to the soil surface, where a hydrophone streamer picks it up. In figure 5 we see operating principles for seismic refraction clearly.by plotting the first time of arrival of the refracted waves versus distance from the seismic source, time-distance curves are produced. The analysis of the slope of these curves provides a direct determination of the depth of the various soil layers. The compression wave velocity $(\mathrm{Vp})$ provides the geoscientist with information that can be used to characterise each soil layer. The main weakness of the method is that it falls short in resolving inversion velocity problems.

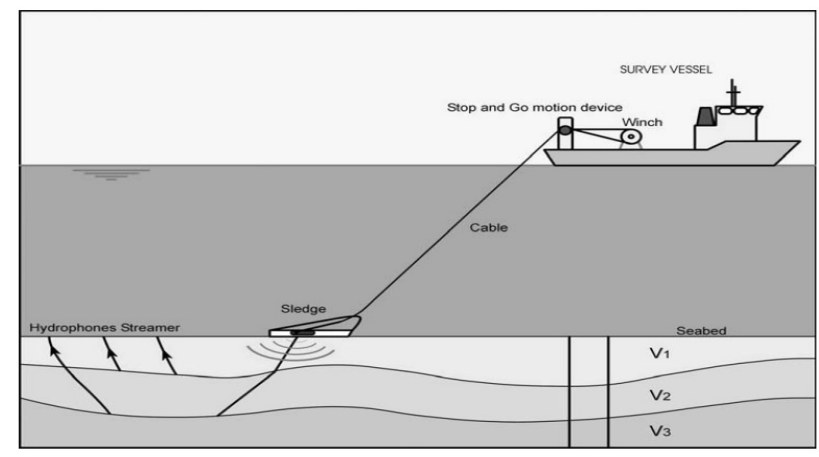

Fig. 5. Operating principles for seismic refraction

\section{Electrical Resistivity Systems}

Seabed electrical resistivity profiling is a semi-continuous method of measuring the bulk resistivity of a volume of soil near the seabed. The technique uses a towed sled from which is towed a multi-electrode streamer cable. For surveys requiring soil penetration depths of $3 \mathrm{~m}$ to $5 \mathrm{~m}$, for example cable burial assessment, streamer lengths are typically $20 \mathrm{~m}$. By injecting an electrical square wave current into the seabed through a pair of electrodes (A and B in Figure 6 ) an electrical potential is created that can be measured between the reference electrode $(\mathrm{N})$ and, typically, 13 electrodes (M1 ... M13). The resistivity of the ambient seawater is measured using a short, low-intensity, square wave injected into the sea by a short quadripole antenna. The ratio of seabed resistivity to that of the seawater is called the formation factor. The potential difference is measured at each of the 13 electrodes at a sampling rate from $1 \mathrm{~Hz}$ to 10 Hz. [8]

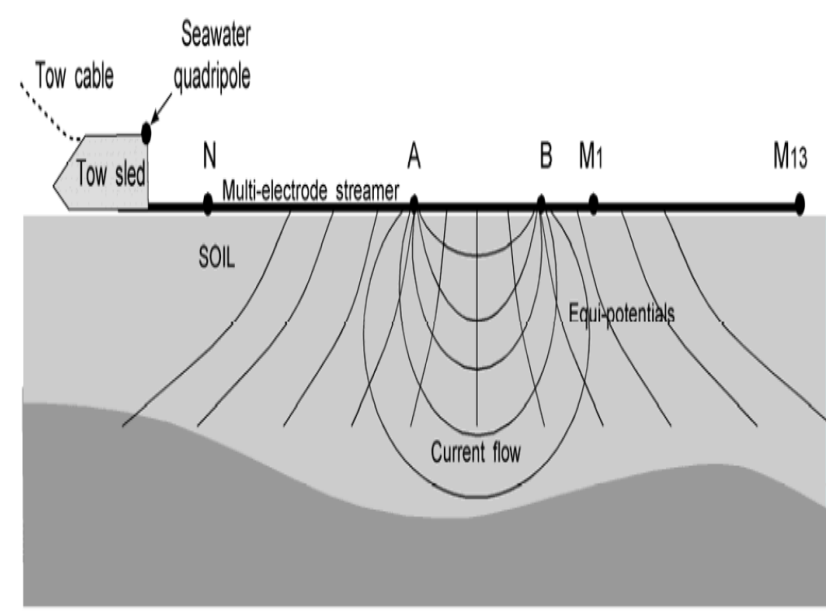

Fig. 6. Electrical resistivity principles

\section{Seabed Classification Systems}

A capability to classify seabed material without the need for costly sampling devices has obvious advantages. Seabed classification systems exist and their effectiveness is improving; however, they are not yet a panacea.Seabed classification is a processed solution requiring a proprietary software and electronics package. The measures of roughness and hardness combined can provide quantitative information on seabed types, but will not be reliable enough to determine detailed soil characteristics. Sidescan sonar can identify seabed morphological boundaries very well.in figure 7 Basic principles of a seabed classification system are explained. In this way, a reliable model of the seabed topsoil is possible.Seabed classification using remote sensing is a rapid method that does not require additional in-sea equipment. However, sidescan or multibeam backscatter data is necessary to detect seabed objects, determine the morphological boundaries and, if reliable seabed interpretation is required, ground truth seabed samples are required. [9],[10] 


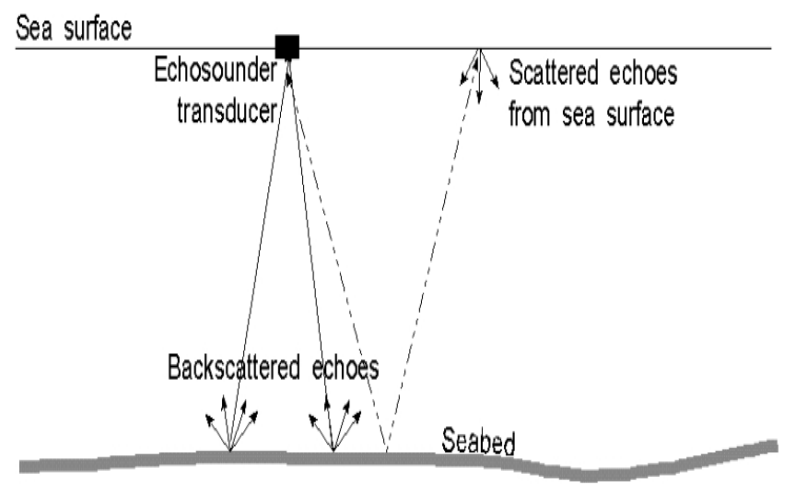

Fig. 7. Basic principles of a seabed classification system

\section{Underwater Cameras}

The visualising systems used for structural inspection can often assist in solving remotely sensed ambiguities. In-situ examination of uncontaminated soil colour, condition and context provide valuable information to the geologist or benthic scientist for environmental assessment and impact studies. However, daylight tends to become totally absorbed in seawater below $300 \mathrm{~m}$ to $500 \mathrm{~m}$. Two options are available:

i. Camera lighting systems.

ii. Low-light cameras.Lighting systems are housed in pressure housings and a variety of light emission types are available.

Lowlight cameras depend on light-enhancement systems (like night-vision glasses), while in extreme dark, solidstate photon detectors are used to collect any available light.The most common form of deployment for lightweight cameras (stills, video) is by diver.

\section{References}

1. Atkins, W. S, In J. H. Barne, C. F. Robson, S. S. Kaznowska, J. P. Doody, N. C. Davidson \& A. L. Buck, Offshore geology, Coasts and Seas of the United Kingdom: Region 17 Northern Ireland. Peterborough. 1997

2. Danson. E, Consultants.S, Geotechnical \& Geophysical Investigations For Offshoreand Nearshore Developments, International Society for Soil.2003.

3. ENGINEERING SERVICE CENTER, Handbook for Marine Geotechnical Engineering. Port Hueneme, California,2011

4. Kolk, H.J. and Wegerif, J. , "Offshore Site Investigations: New Frontiers", International Symposium on Frontiers in Offshore Geotechnics ISFOG, Perth, Western Australia.2005

5. Poulos ,H.G, Marine Geotechnics, Spon Press; 1 edition, 1988
6. Quinn. R, Marine geophysical investigation of the inshore coastal waters of Northern Ireland, The International Journal of Nautical Archaeology,2000, 29.2: 294-298

7. Handbook for Marine Geotechnical Engineering, Engineering Service Center, SP-2209-OCN, 15 March 2011

8. Guidance Notes On Geotechnical Investigations For Marine Pipelines, The Society for Underwater Technology, OSIG Rev 03, 2004,

9. Barto Arnold III, J., Oertling, T. J. \& Hall, A. W., 1999, The Denbigh project: initial observations on a Civil War blockaderunner and its wreck-site. IJNA, 28: 126-144.

10.Redknap, M., 1990, Surveying for underwater archaeological sites: signs in the sands. The Hydrographic Journal, 58: 11-16. 